\title{
SISTEM PENDUKUNG KEPUTUSAN PENERIMAAN DEBITUR MENGGUNAKAN METODE TOPSIS (STUDI KASUS: SWAMITRA KSP INTRANZ)
}

\author{
Phitsa Mauliana $^{1)}$, Nanang Hunaifi ${ }^{2)}$, Frendi Wahyudi ${ }^{3)}$ \\ Program Studi Komputerisasi Akuntansi ${ }^{1)}$, Program Studi Manajemen Informatika ${ }^{2)}$, \\ Program Studi Tehnik Informatika ${ }^{3)}$ \\ AMIK BSI Bandung ${ }^{12)}$, Universitas BSI Bandung ${ }^{3)}$ \\ phitsa.phu@bsi.ac.id ${ }^{1)}$, nanang.nnu@bsi.ac.id ${ }^{2}$, frndwhyd@ gmail.com ${ }^{3)}$
}

\begin{abstract}
ABSTRAK
Proses penerimaan debitur baru pada Swamitra KSP Intranz masih menggunakan menggunakan cara manual dengan memeriksa data satu persatu dokumen yang telah diminta dari debitur atau calon debitur dan menghasilkan keputusan yang masih subjektif dan belum sepenuhnya akurat. Penggunaan Sistem Pendukung Keputusan dapat membantu untuk memberikan nilai kepada setiap alternatif dan menghasilkan keputusan yang akurat serta objektif. Sistem Pendukung Keputusan penerimaan debitur dibuat menggunakan metode TOPSIS (Technique For Orders Reference by Similarity to Ideal Solution). Teknik TOPSIS sangat membantu para pengambil keputusan untuk menyusun struktur masalah yang harus dipecahkan, melakukan analisis, perbandingan dan peringkat alternatif. Sistem Pendukung keputusan ini dibuat berbasis web. Penerimaan debitur ini menggunakan 5 (lima) kriteria yaitu; penghasilan, jumlah tanggungan, swachecking dan jaminan, kemudian nilai bobot dari 5 (lima) kriteria tersebut dihitung menggunakan metode TOPSIS. Nilai tertinggi dari hasil perhitungan nilai bobot kriteria menjadi yang paling direkomendasikan untuk diterima pengajuan kreditnya.
\end{abstract}

Kata Kunci: Sistem Pendukung Keputusan, TOPSIS, Debitur

\section{PENDAHULUAN}

Menurut Firdaus dan Aryanti ${ }^{[1]}$, Kegiatan perkreditan tentunya tidak terlepas dari peran serta debitur (orang yang menerima pinjaman). Debitur tersebut juga merupakan salah satu unsur-unsur kredit. Debitur merupakan unsur atau pihak yang penting dalam kegiatan perkreditan, karena apabila debitur tidak mengembalikan kredit maka bisa dipastikan usaha bank tersebut akan mengalami kebangkrutan.

Debitur merupakan pihak yang membutuhkan atau meminjam uang, barang, dan jasa Dalam menentukan penerimaan kredit ada beberapa kriteria yang ditentukan oleh bank. Setiap bank memiliki kriteria-kriteria dan menentukan bobot pada setiap kriteria saat melakukan pengecekan data debitur untuk pengejuan kredit. Hasil dari pengolahan data selanjutnya dipergunakan oleh bagian analis kredit di bank untuk menentukan apakah pengajuan kredit bisa diterima atau tidak. Oleh karena itu, untuk memudahkan pihak bank dalam pengambilan keputusan penerimaan debitur untuk mengajukan kredit diperlukan Aplikasi Sistem Pendukung Keputusan.

Menurut sumber ${ }^{[2]}$ sistem pendukung keputusan merupakan program komputer yang secara khusus dapat membantu menyelesaikan masalah semi terstruktur yang secara interaktif, fleksibel dan mudah beradaptasi dengan permasalahan yang dihadapi oleh suatu organisasi, sehingga mempermudah decision maker dalam menganalisis, memecahkan dan pengambilan keputusan suatu masalah organisasi.

Metode yang dapat digunakan sebagai alat untuk pengambilan keputusan adalah metode TOPSIS (Technique for Order Preference by Similarity to Ideal Solution). Teknik TOPSIS sangat membantu para pengambil keputusan untuk menyusun struktur masalah yang harus dipecahkan, melakukan analisis, perbandingan dan peringkat alternatif.

Dalam menentukan penerimaan kredit pada Swamitra KSP Intranz terdapat 5 (lima) kriteria dan bobot yang telah di tentukan oleh 
perusahaan. kriteria yang digunakan adalah rekening listrik, slip gaji, jumlah tanggungan, jaminan, dan swachecking. Proses penentuan kelayakan kredit tersebut masih menggunakan menggunakan cara manual dengan memeriksa data satu persatu dokumen yang telah diminta dari debitur atau calon debitur dan menghasilkan keputusan yang masih subjektif dan belum sepenuhnya akurat. Hasil pemeriksaan berkas digunakan untuk menentukan penerimaan kredit oleh pihak manager Swamitra KSP Intranz.

\section{KONSEP METODE TOPSIS}

Pada penelitian ini digunakan metode TOPSIS untuk menentukan dan mengolah kriteria-kriteria dari alternatif yang ada. Menurut Sachdeva dkk ${ }^{[3]}$ TOPSIS dikenalkan pertamakali oleh Yoon dan Hwang pada tahun 1981 untuk digukan sebagai salah satu metode dalam memecahkan masalah multikriteria.

TOPSIS memilih alternatif paling dekat dengan solusi ideal dan terjauh dari alternatif ideal negatif. Metode TOPSIS didasarkan pada informasi atribut dari pembuat keputusan, solusinya ditujukan untuk mengevaluasi, memprioritaskan dan memilih dan satu-satunya input subjektif dengan menggunakan bobot.

Proses algoritma TOPSIS dimulai dengan pembentukan matriks keputusan untuk mewakili nilai solusi ideal dari setiap kriteria dengan setiap alternatif.

Prosedur ideal untuk perhitungan menggunakan metode TOPSIS dapat mengikuti langkah-langkah sebagai berikut: ${ }^{[4,5]}$

a. Langkah pertama adalah buat matriks keputusan dan tentukan bobot kriteria. Dimana $X=\left(\mathrm{x}_{\mathrm{ij}}\right)$ menjadi matriks keputusan dan $\mathrm{W}=\left(\mathrm{W}_{1}, \mathrm{~W}_{2}, \ldots, \mathrm{W}_{\mathrm{n}}\right)$ adalah vektor bobot,dimana $\mathrm{x}$ ij $\in \mathfrak{R}, \mathrm{w}_{\mathrm{j}} \in \mathfrak{R}$ dan $\mathrm{w}_{1}+\mathrm{w}_{2}+\ldots+\mathrm{w}_{\mathrm{n}}=1$

Kriteria fungsi dapat berupa: fungsi manfaat (lebih banyak lebih baik) atau fungsi biaya (kurang lebih baik).

b. Langkah kedua adalah hitung matriks keputusan yang dinormalkan.

Langkah ini mengubah berbagai dimensi atribut menjadi non-dimensi atribut yang memungkinkan perbandingan antar kriteria. Karena beragam kriteria biasanya diukur dalam berbagai unit, skor dalam matriks evaluasi $\mathrm{X}$ harus diubah menjadi skala normal. Normalisasi nilai dapat dilakukan oleh salah satu dari beberapa formula standar yang diketahui.

Beberapa metode yang paling sering digunakan untuk menghitung nilai normalisasi adalah sebagai berikut :

$$
n_{i j}=\frac{x_{i j}}{\sqrt{\sum_{i=1}^{m} x_{i j}^{2}}}
$$

c. Hitung matriks keputusan yang dinormalisasi tertimbang. Nilai normalisasi tertimbang $\mathrm{v}_{\mathrm{ij}}$ dihitung dengan cara berikut:

$$
v_{i j}=w_{j} n_{i j} \text { for } i=1, \ldots, m ; j=1, \ldots, n \text {. }
$$

Dimana $w_{j}$ adalah bobot dari kriteria

$$
\sum_{i=1}^{n} w_{j}=1 \text {. }
$$

d. Tentukan solusi ideal negatif dan ideal positif. Identifikasi alternatif ideal positif dan identifikasi alternatif ideal negatif Solusi positif yang ideal adalah solusi yang memaksimalkan manfaat kriteria dan meminimalkan kriteria biaya sedangkan solusi ideal negatif memaksimalkan kriteria biaya dan meminimalkan kriteria manfaat.

Solusi ideal yang positif $\mathrm{A}^{+}$memiliki bentuk:

$$
A^{+}=\left(v_{1}^{+}, v_{2}^{+}, \ldots, v_{n}^{+}\right)=\left(\left(\operatorname{maxx}_{i j} \mid j \in I\right),\left(\operatorname{minv}_{i j} \mid j \in J\right)\right) \text {. }
$$

Negative ideal solution $A^{-}$has the form:

$$
\left.A^{-}=\left(v_{1}^{-}, v_{2}^{-}, \ldots, v_{n}^{-}\right)=\left(\left(\min _{\left.v_{i j} \mid j \in I\right)}\right), \max _{i_{j}} \mid j \in J\right)\right)
$$

e. Hitung langkah-langkah pemisahan dari solusi ideal positif dan solusi ideal negatif. Pemisahan setiap alternatif dari solusi ideal positif digunakan rumus sebagai berikut :

$$
d_{i}^{+}=\left(\sum_{j=1}^{n}\left(v_{i j}-v_{j}^{+}\right)^{p}\right)^{1 / p}, i=1,2, \ldots, m .
$$


Pemisahan setiap alternatif dari solusi ideal negatif digunakan rumus sebagai berikut :

$d_{i}^{-}=\left(\sum_{j=1}^{n}\left(v_{i j}-v_{j}^{-}\right)^{p}\right)^{1 / p}, i=1,2, \ldots, m$

f. Menentukan kedekatan setiap alternatif terhadap solusi ideal dengan rumus sebagai berikut :

$$
R_{i}=\frac{d_{i}^{-}}{d_{i}^{-}+d_{i}^{+}}
$$

Dimana :

$0 \leq R_{i} \leq 1, i=1,2, \ldots, m$.

g. Buat peringkat urutan preferensi atau pilih alternatif yang paling dekat dengan 1 .

Satu set alternatif dapat digolongkan berdasarkan urutan nilai dari $\mathrm{R}_{\mathrm{i}}$.

\section{ANALISIS \\ PERANCANGAN}

DAN

\section{Penentuan Variabel}

Pada metode TOPSIS yang digunakan peneliti kali ini, ditentukan 5 kriteria untuk menentukan penerimaan debitur baru, kriteria tersebut adalah sebagai berikut:

Tabel 1. Kriteria Metode TOPSIS

\begin{tabular}{|l|l|l|}
\hline Kode & Kriteria & $\begin{array}{l}\text { Jenis } \\
\text { Kriteria }\end{array}$ \\
\hline C1 & Pembayaran Rekening Listrik & biaya \\
\hline C2 & Slip Gaji & keuntungan \\
\hline C3 & Jumlah Tanggungan & biaya \\
\hline C4 & Jaminan BPKB/Surat Tanah & keuntungan \\
\hline C5 & Swa Checking & biaya \\
\hline
\end{tabular}

Dari kriteria tersebut diberikan bobot pada masing-masing kriteria yang di jabarkan sebagai berikut:

Tabel 2. Bobot Kriteria Metode TOPSIS

\begin{tabular}{|l|l|l|}
\hline Kode & Kriteria & Bobot \\
\hline C1 & Pembayaran Rekening Listrik & 3 \\
\hline C2 & Slip Gaji & 4 \\
\hline C3 & Jumlah Tanggungan & 2 \\
\hline
\end{tabular}

\begin{tabular}{|l|l|l|}
\hline C4 & Jaminan BPKB/Surat Tanah & 5 \\
\hline C5 & Swa Checking & 2 \\
\hline
\end{tabular}

Pemberian bobot kriteria diambil berdasarkan acuan sebagai berikut:

\begin{tabular}{|c|c|}
\hline Jenis Kriteria & Nilai Acuan Bobot \\
\hline \multirow[t]{2}{*}{$\begin{array}{l}\text { Pembayaran Rekening } \\
\text { Listrik }\end{array}$} & Lancar (5) \\
\hline & Tidak Lancar (2) \\
\hline \multirow[t]{5}{*}{ Slip Gaji } & $<1 \mathrm{jt}(1)$ \\
\hline & $<2 \mathrm{jt}(2)$ \\
\hline & $<3$ jt (3) \\
\hline & $<4$ jt (4) \\
\hline & $<5$ atau lebih $(5)$ \\
\hline \multirow[t]{5}{*}{ Jumlah Tanggungan } & tidak ada (5) \\
\hline & 1 orang $(4)$ \\
\hline & 2 orang (3) \\
\hline & 3 orang (2) \\
\hline & $>4$ orang $(1)$ \\
\hline \multirow[t]{4}{*}{ Jaminan BPKB/Surat Tanah } & akta tanah (5) \\
\hline & sertifikat rumah (4) \\
\hline & BPKB Mobil(3) \\
\hline & BPKB Motor(2) \\
\hline \multirow[t]{5}{*}{ Swa Checking } & tidak bermasalah (5) \\
\hline & coll $1(4)$ \\
\hline & coll $2(3)$ \\
\hline & $\operatorname{coll} 3(2)$ \\
\hline & coll $4(1)$ \\
\hline
\end{tabular}

\section{Perhitungan Metode TOPSIS}

Setelah menentukan kriteria dan bobot kriteria, selanjutnya adalah menghitung dari contoh data menggunakan ketentuan dari persamaan metode TOPSIS, berikut adalah contoh nya:

Tabel 4. Data Calon Debitur

\begin{tabular}{|l|c|c|c|c|c|}
\hline Kode & C1 & C2 & C3 & C4 & C5 \\
\hline A1 & 5 & 3 & 3 & 3 & 5 \\
\hline A2 & 5 & 2 & 5 & 3 & 2 \\
\hline A3 & 5 & 4 & 2 & 4 & 5 \\
\hline
\end{tabular}

Langkah pertama adalah membentuk matrik keputusan ternormalisasi terbobot menggunakan rumus ${ }^{(1)}$ : 


$$
\begin{aligned}
& \mathrm{X} 1=8.660254 \\
& \mathrm{R} 11=0.57735 \\
& \mathrm{R} 21=0.57735 \\
& \mathrm{R} 31=0.57735 \\
& \mathrm{X} 2=5.385165 \\
& \mathrm{R} 12=0.557086 \\
& \mathrm{R} 22=0.371391 \\
& \mathrm{R} 32=0.742781 \\
& \mathrm{X} 3=6.164414 \\
& \mathrm{R} 13=0.486664 \\
& \mathrm{R} 23=0.811107 \\
& \mathrm{R} 33=0.324443 \\
& \mathrm{X} 4=5.830952 \\
& \mathrm{R} 14=0.514496 \\
& \mathrm{R} 24=0.514496 \\
& \mathrm{R} 34=0.685994 \\
& \mathrm{X} 5=7.348469 \\
& \mathrm{R} 15=0.680414 \\
& = \\
& \mathrm{R} 25=0.272166 \\
& = \\
& \mathrm{R} 35=0.680414 \\
& =
\end{aligned}
$$

\begin{tabular}{|l|l|l|l|l|l|}
\hline $\mathrm{R}=$ & 0.577 & 0.5570 & 0.4866 & 0.5144 & 0.6804 \\
\hline & 0.577 & 0.3713 & 0.8111 & 0.5144 & 0.2721 \\
\hline & 0.577 & 0.7427 & 0.3244 & 0.6859 & 0.6804 \\
\hline
\end{tabular}

Selanjutnya memberi pembobotan pada setiap kriteria menggunakan rumus ${ }^{(2)}$ :

\begin{tabular}{|l|l|l|l|l|l|}
\hline $\mathrm{Y}=$ & 1.7320 & 2.2283 & 0.9733 & 2.5724 & 1.3608 \\
\hline & 1.7320 & 1.4855 & 1.6222 & 2.5724 & 0.5443 \\
\hline & 1.7320 & 2.9711 & 0.6488 & 3.4299 & 1.3608 \\
\hline
\end{tabular}

Menentukan solusi ideal positif dan solusi ideal negatif menggunakan rumus ${ }^{(3)}$ :

$\begin{array}{lll}y 1^{+} & \operatorname{MIN}(1.732051 ; 1.732051 ; 1.732051)= & 1.732051 \\ y 2^{+} & \operatorname{MAX}(2.228344 ; 1.485563 ; 2.971125)= & 2.971125 \\ y 3^{+} & \operatorname{MIN}(0.973329 ; 1622214 ; 0.648886)= & 0.648886 \\ y 4^{+} & \operatorname{MAX}(2.572479 ; 2.572479 ; 3.429972)= & 3.429972 \\ y 5^{+} & \operatorname{MIN}(1.360828 ; 0.544331 ; 1.360828)= & 0.544331 \\ A^{+} & (1.732051 ; 2.971125 ; 1.0 .648886 ; & \\ & 3.429971 ; 0.544331) & \\ y 1^{-} & \operatorname{MAX}(1.732051 ; 1.732051 ; 1.732051)= & 1.732051 \\ y 2^{-} & \operatorname{MIN}(2.228344 ; 1.485563 ; 2.971125)= & 1.485563 \\ y 3^{-} & \operatorname{MAX}(0.973329 ; 1622214 ; 0.648886)= & 1.622214 \\ y 4^{-} & \operatorname{MIN}(2.572479 ; 2.572479 ; 3.429972)= & 2.572479\end{array}$

$y 5^{-} \quad \operatorname{MAX}(1.360828 ; 0.544331 ; 1.360828)=1.360828$ $A^{-} \quad(1.732051 ; 1.45563 ; 1.522214$ ;2.572479;1.360828)

menghitung jarak solusi ideal positif dengan rumus $^{(4)}$ :

$$
\begin{array}{ll}
\mathrm{D}^{+} & =1.4349 \\
\mathrm{D}^{+} & =1.9721 \\
\text { D3 }^{+} & =0.8164
\end{array}
$$

jarak solusi ideal negatif dengan rumus ${ }^{(5)}$ :

$$
\begin{array}{ll}
\text { D1 }^{-} & =0.9862 \\
\text { D2 }^{-} & =0.8164 \\
\text { D3 }^{-} & =1.9721
\end{array}
$$

menentukan setiap preferensi pada setiap alternatif menggunakan rumus ${ }^{(6)}$ :
$\mathrm{V} 1=$
0.407358
$\mathrm{V} 2=$
0.292788
$\mathrm{V} 3=$
0.707212

Dari hasil perhitungan di atas dapat diketahui bahwa alternatif ke 3 memiliki nilai paling tinggi. Jadi berdasarkan perhitungan tersebut debitur baru yang paling berhak untuk diterima kreditnya adalah alternatif ke 3 .

\section{Rancangan Sistem}

\section{1) Use case Diagram}

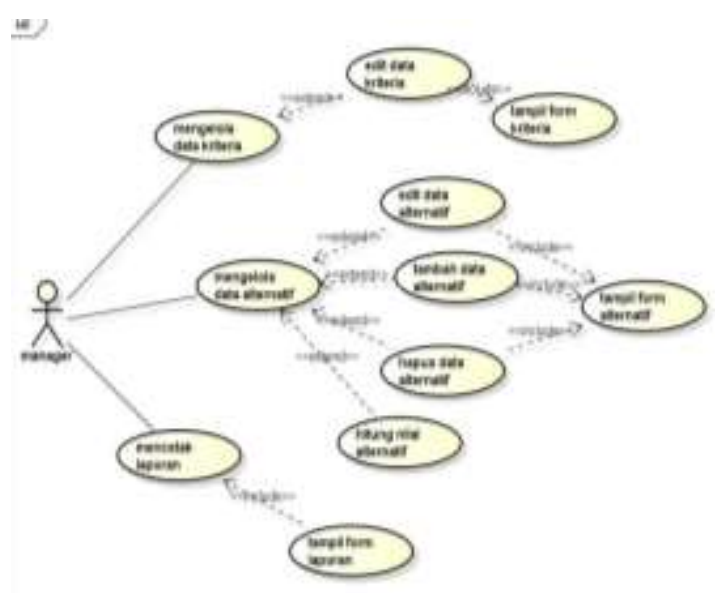

Gambar 1. Use Case Diagram 


\section{2) Activity Diagram Edit Bobot Kriteria}

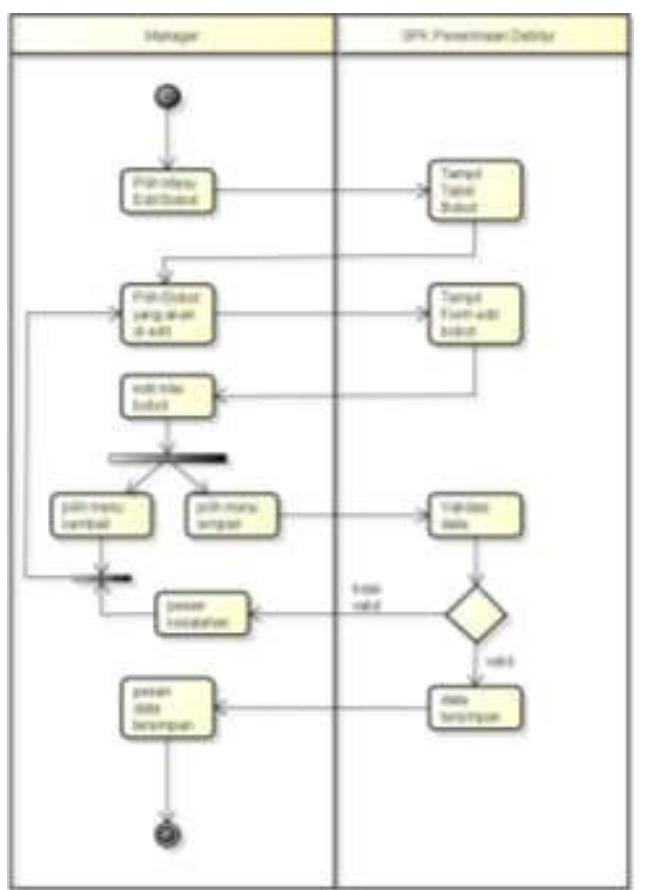

Gambar 2. Activity Diagram Edit Bobot Kriteria

3) Acivity Diagram Proses Hitung Alternatif dan Cetak

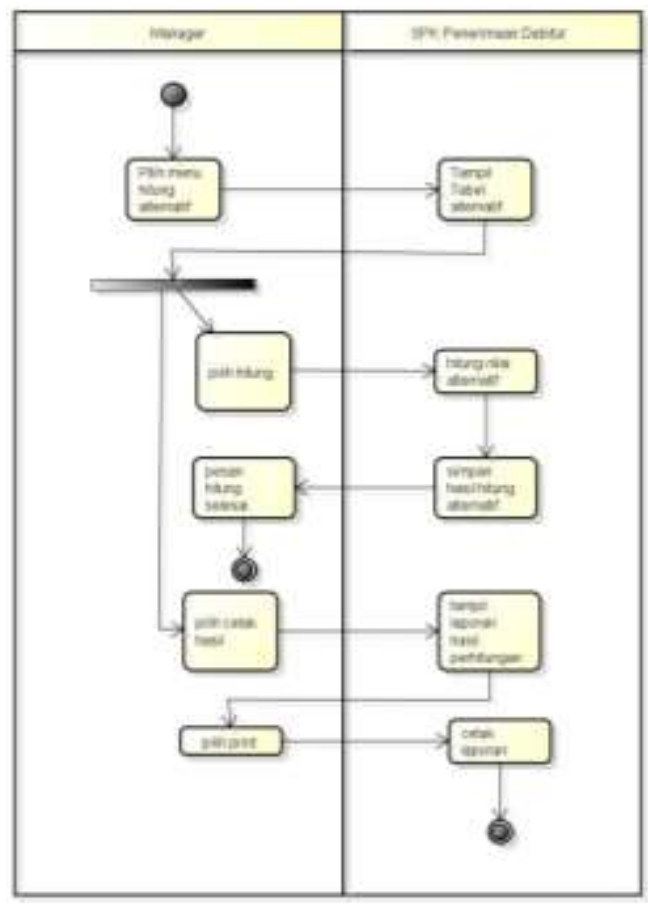

Gambar 3. Activity Diagram Proses Hitung Alternatif dan Cetak

\section{Rancangan User Interface}

Hasil dari tampilan program yang dibuat oleh penulis adalah sebagai berikut :

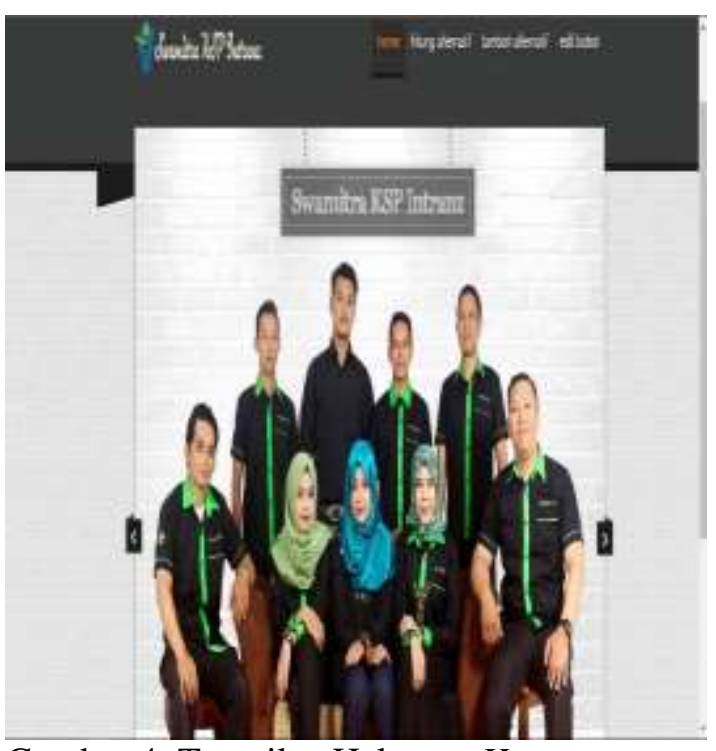

Gambar 4. Tampilan Halaman Home 


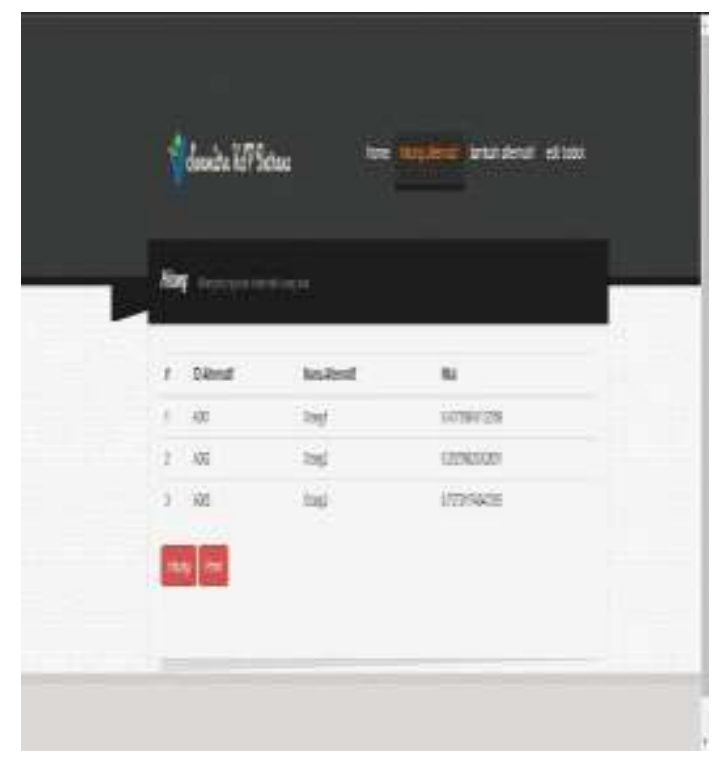

Gambar 5. Tampilan Hitung Alternatif

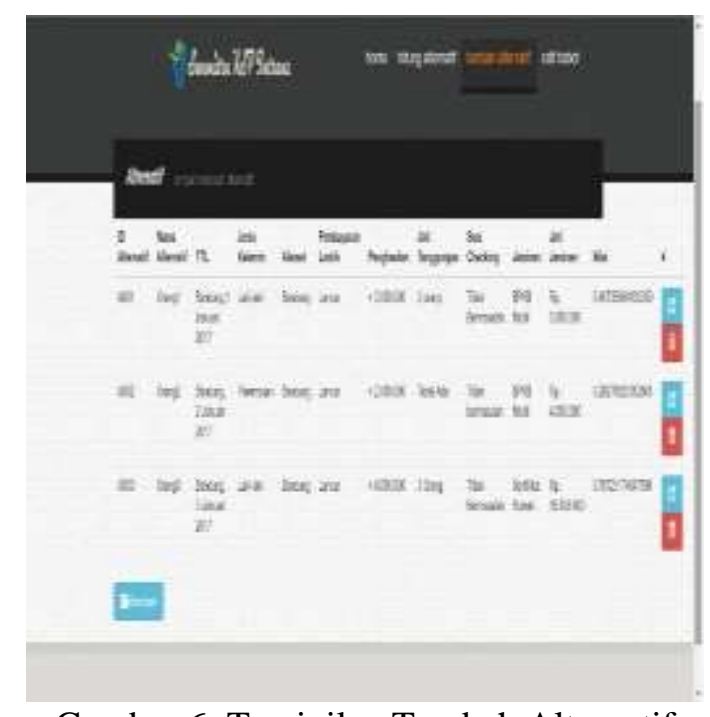

Gambar 6. Tamipilan Tambah Alternatif

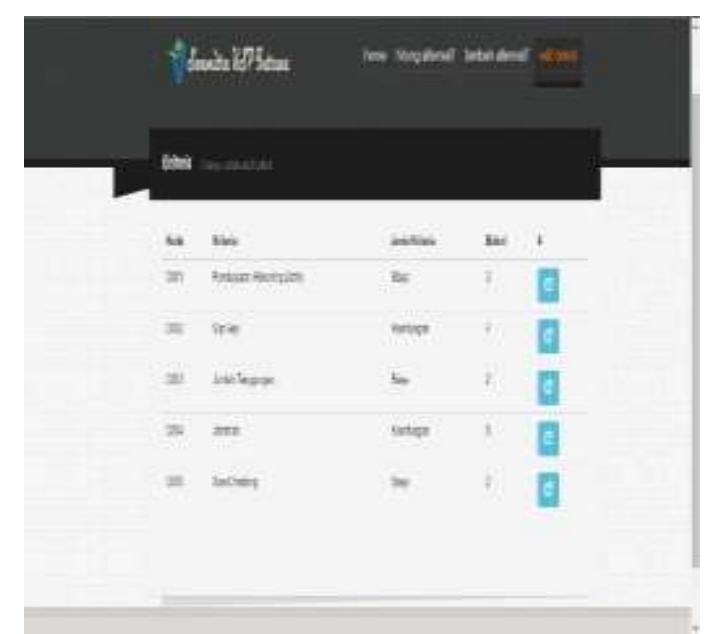

Gambar 7. Tampilan Edit Bobot

\section{PENUTUP}

Dari hasil penelitian diatas dapat diambil kesimpulan sebagai berikut :

1. Telah dihasilkan suatu Sistem Pendukung Keputusan penerimaan debitur pada Swamitra KSP Intranz.

2. Penerapan metode TOPSIS dapat menghasilkan laporan data debitur yang akurat sehingga membantu manager dalam menentukan penerima pengajuan kredit pada Swamitra KSP Intranz.

3. Untuk penelitian selanjutnya dapat dikembangkan aplikasi berbasis mobile, agar hasil perhitungan dapat dilihat kapanpun dan dimanapun

4. Untuk penelitian mengenai penerimaan debitur selanjutnya dapat menggunakan metode lain dalam proses perhitungan.

\section{Daftar Pustaka}

[1] Firdaus, R. H., \& Aryanti, M. (2003). Manajemen Perkreditan Bank. Bandung: Alfabeta.

[2] Turban, E. (1995) Decision Support System and Expert System, United State : Prentice Hall Internasional.

[3] Sachdeva, A., Kumar, D., \& Kumar, P. (2009). Multi-factor failure mode critically analysis using TOPSIS. Journal of Industrial Engineering International, 19.

[4] Chen S.J., Hwang C.L. (1992): Fuzzy Multiple Attribute Decision Making: Methods and Applications. SpringerVerlag, Berlin.

[5] Jahanshahloo G.R., Lofti F.H., Izadikhah M. (2006): An Algorithmic Method to Extend TOPSIS for Decision Making Problems with Interval Data. "Applied Mathematics and Computation. 